\title{
The Endoplasmic Reticulum as the Site of Potassium Tellurite Reduction in Yeasts
}

\author{
By PAULINE S. CORFIELD* AND D. G. SMITH \\ Department of Botany and Microbiology, University College, London W.C.I
}

(Accepted for publication 25 August 1970)

\begin{abstract}
SUMMARY
Potassium tellurite $\left(\mathrm{K}_{2} \mathrm{TeO}_{3}\right)$ reduction in the obligate aerobe Rhodotorula mucilaginosa 49 and the facultative anaerobe Saccharomyces cerevisiae $\mathbf{I}-434$ occurs on localized areas of endoplasmic reticulum. The reduction product is granular and is found in close association with the membranes of specific parts of the endoplasmic reticulum. The site of reduction is the same whether $R$. mucilaginosa 49 is grown on a respiratory substrate (sodium malate) or a fermentable substrate (glucose).

Increasing concentrations of $\mathrm{K}_{2} \mathrm{TeO}_{3}$ increasingly inhibit the growth of Rhodotorula mucilaginosa 49. Its rate of oxygen uptake is not altered when grown in the presence of $0.04 \% \mathrm{~K}_{2} \mathrm{TeO}_{3}$, but in Saccharomyces cerevisiae I-434 it decreases under the same conditions. Growth of $S$. cerevisiae I-434 is completely inhibited with glycerol as substrate in the presence of $\mathrm{K}_{2} \mathrm{TeO}_{3}$.
\end{abstract}

\section{INTRODUCTION}

The reduction of potassium tellurite $\left(\mathrm{K}_{2} \mathrm{TeO}_{3}\right)$ to a black insoluble compound by living tissues is generally regarded as indicating enzymic oxidation reduction processes and, at the ultrastructural level, as indicating the localization of certain enzymes or enzyme systems.

Barnett \& Palade (1957) showed that in mammalian heart tissue with succinate as substrate tellurite was reduced mainly in the mitochondria, and this observation was interpreted as providing a basis for a histochemical method for demonstrating the presence of a mitochondrial succinic dehydrogenase.

Different sites for reduction of $\mathrm{K}_{2} \mathrm{TeO}_{3}$ in bacteria have been reported. It is said to occur on the mesosomal membranes in Bacillus subtilis and the mesosome is consequently ascribed a respiratory function (van Iterson \& Leene, 1964). In most other bacteria the reduction product is not associated with mesosomal membranes but instead occurs either near the cytoplasmic membrane (Tchan \& Webber, 1966) or randomly in the cytoplasm (Brieger, I963). Most workers reporting on reduction of $\mathrm{K}_{2} \mathrm{TeO}_{3}$ in bacteria have been unaware of the mechanism of the reaction, as substrates were not carefully controlled. However, Nermut (1967), using glycine as the substrate, localized glycine oxidase activity in Proteus vulgaris when $\mathrm{K}_{2} \mathrm{TeO}_{3}$ was the electron acceptor. Tellurium deposits were found only in the close vicinity of the plasmalemma.

Nickerson (1954) noticed that in Candida albicans tellurite was reduced to black

* Present address: Department of Bacteriology and Virology, University of Manchester, Brunswick Street, Manchester 13. 
metallic tellurium and selenite to red metallic selenium. Reduction of both was confined to particulate loci visible in light micrographs.

Nagai (1965) found that colonies of respiratory deficient (petites) and respiratory competent (normal) Saccharomyces species varied in their reduction of tellurite depending on culture conditions. Normal colonies turned black while petite colonies remained nearly white, but addition of ammonium sulphate to the medium weakened and sometimes completely reversed the effect. Nagai considered tellurite reduction only as a means of differentiating between petites and normal Saccharomyces colonies.

The present investigation demonstrates that both Rhodotorula mucilaginosa and Saccharomyces cerevisiae reduce $\mathrm{K}_{2} \mathrm{TeO}_{3}$. The effects of tellurite on growth and respiration have been studied, and the sites of reduction investigated at the ultrastructural level.

\section{METHODS}

Organisms. The strains used were Rhodotorula mucilaginosa 49, an obligate aerobe, and Saccharomyces cerevisiae I-434, a facultative anaerobe.

Media. Rhodotorula mucilaginosa 49 was grown in a medium containing (g./1.): glucose, 20; or sodium malate, 20 ; and $\left(\mathrm{NH}_{4}\right)_{2} \mathrm{SO}_{4}, 20 ; \mathrm{KH}_{2} \mathrm{PO}_{4}, 20$; yeast extract, 5; in distilled water. Saccharomyces cerevisiae $\mathrm{I}-434$ was grown in a medium containing (g./1.): glucose 20; or glycerol, 40; Bacto-peptone, 20; yeast extract, I0; in distilled water.

Growth measurements. Both organisms were grown up to midlogarithmic growth phase, and $0.5 \mathrm{ml}$. samples were inoculated into $50 \mathrm{ml}$. of the appropriate medium in conical flasks, and shaken at $30^{\circ}$. For experiments with $\mathrm{K}_{2} \mathrm{TeO}_{3}$, a $0.4 \%$ aqueous solution was membrane-filtered, and added aseptically to give a final concentration of $0.04 \%$. Growth of the population was followed by counting yeast cells in a haemocytometer. Extinction measurements could not be used because the black reduction product obscured the true rate of growth.

Oxygen uptake measurements. Oxygen uptake was measured at $30^{\circ}$ by means of a Rank Oxygen electrode coupled to a chart recorder.

Electron Microscopy. Samples of Rhodotorula mucilaginosa 49 were harvested, washed in distilled water and fixed in $1 \%$ unbuffered-aqueous potassium permanganate for $20 \mathrm{~min}$ at room temperature. Saccharomyces cerevisiae $1-434$ cells were fixed for $\mathrm{I} h$. in the same fixative. After centrifuging and washing, the cells were maintained as a pellet, dehydrated in tertiary butyl alcohol mixtures (Johansen, I940) and embedded in Araldite. Sections were mounted on formvar-coated grids and examined in a Siemens Elmiskop I or a Zeiss EM 9. Sections were poststained for $30 \mathrm{~min}$. in $50 \%(\mathrm{v} / \mathrm{v})$ ethyl alcohol saturated with uranyl acetate followed by $2 \mathrm{~min}$. in lead citrate (Reynolds, I963).

\section{RESULTS}

\section{Effect of potassium tellurite on normal growth of yeasts}

In the glucose-salts medium in the presence of $\mathrm{K}_{2} \mathrm{TeO}_{3}$ the growth of Rhodotorula mucilaginosa 49 was inhibited. The effects of 0.04 and $0.08 \% \mathrm{~K}_{2} \mathrm{TeO}_{3}$ on the size of the final stationary population and the mean generation time are presented in Table $\mathbf{I}$.

In liquid medium with glucose as the fermentable substrate, Saccharomyces cerevisiae I-434 multiplied and reduced $\mathrm{K}_{2} \mathrm{TeO}_{3}$. However, tellurite was finally toxic and the 
growth rates were reduced in a way similar to those of Rhodotorula mucilaginosa 49. On the non-fermentable substrate glycerol both concentrations of tellurite completely inhibited growth.

Oxygen uptake of yeasts grown in the presence of $\mathrm{K}_{2} \mathrm{TeO}_{3}$

As $\mathrm{K}_{2} \mathrm{TeO}_{3}$ profoundly affected growth of both yeasts it was decided to investigate whether or not it caused inhibition of respiration. The oxygen uptake of exponentially growing cultures of Rhodotorula mucilaginosa 49 in glucose + salts medium in the presence and absence of tellurite was measured; the $\mathrm{K}_{2} \mathrm{TeO}_{3}$ concentrations were 0.04 and $0.08 \%$. The same number of centrifuged and washed yeast cells were used for all treatments. The cell suspensions were shaken at $30^{\circ}$ during the experiment. Sodium azide, a known inhibitor of respiration, was added to test the sensitivity of the system.

Table I. The effect of $\mathrm{K}_{2} \mathrm{TeO}_{3}$ on the size of the stationary population and on the mean generation time of Rhodotorula mucilaginosa 49

$\begin{array}{lccc} & \text { Control } & 0.04 \% \mathbf{K}_{2} \mathrm{TeO}_{3} 0.08 \% \mathbf{K}_{2} \mathrm{TeO}_{3} \\ \begin{array}{c}\text { Final stationary population as a } \\ \text { percentage of control }\end{array} & 100 & 6 \mathrm{I} & 25 \\ \begin{array}{l}\text { Mean generation time } \\ \mathrm{I}\end{array} & \mathrm{I} \cdot 7 \mathrm{I} \mathrm{h} . & 1.85 \mathrm{~h} . & 2.85 \mathrm{~h} .\end{array}$

Table 2. Summary of oxygen uptake measurements on Rhodotorula mucilaginosa 49 and Saccharomyces cerevisiae I-434

Oxygen uptake rates are expressed as a percentage of the control rate.

\begin{tabular}{lccc}
$\begin{array}{c}\text { Rhodotorula } \\
\text { mucilaginosa } 49\end{array}$ & \multicolumn{2}{c}{$\begin{array}{c}\text { Saccharomyces } \\
\text { cerevisiae }\end{array}$} \\
\cline { 2 - 3 } & Glucose & Glucose & Glycerol \\
$\mathrm{Control}$ & 100 & 100 & I00 \\
$0.04 \% \mathrm{~K}_{2} \mathrm{TeO}_{3}$ & 100 & 36.8 & No growth \\
$0.08 \% \mathrm{~K}_{2} \mathrm{TeO}_{3}$ & 100 & 19.8 & No growth \\
$10^{-3} \mathrm{M}-\mathrm{NaN}_{3}$ & 100 & 0.0 & 0.0
\end{tabular}

The oxygen uptake was identical for all four treatments, indicating that $\mathrm{K}_{2} \mathrm{TeO}_{3}$ did not inhibit growth by a direct effect on the respiratory pathways in Rhodotorula mucilaginosa 49 I $^{-3} \mathrm{M}$-Azide had no discernible effect on oxygen uptake; this is an unexplained result because azide is a potent inhibitor of mitochondrial electron transfer, inhibiting cytochrome $a_{3}$.

Rhodotorula mucilaginosa 49 grown normally to midlogarithmic growth phase and then exposed to 0.04 and $0.08 \% \mathrm{~K}_{2} \mathrm{TeO}_{3}$ also showed no change in oxygen uptake.

Oxygen uptake was also measured for samples of Saccharomyces cerevisiae I-434 grown with glucose as substrate and in the presence of 0.04 and $0.08 \% \mathrm{~K}_{2} \mathrm{TeO}_{3}$. Tellurite lowered the rate of oxygen uptake (Table 2). Sodium azide completely inhibited oxygen uptake by normally grown $S$. cerevisiae I-434 cells.

\section{Electron microscopy of Rhodotorula mucilaginosa 49}

A normal Rhodotorula mucilaginosa 49 cell fixed in potassium permanganate showed well-defined membrane-bounded organelles (Pl. I, fig. I). The mitochondria were 
numerous with well-developed cristae and the central nucleus was enclosed in a double membrane with pores $80 \mathrm{~nm}$. in diameter. A few small vacuoles bounded by a single unit membrane were usually visible.

The endoplasmic reticulum, a system of double membranes forming tubes and flat plates ramifying through the cytoplasm, was not oriented in any particular way in the yeast. It was frequently seen to be in connexion with the nuclear membrane. Unstained sections of midlogarithmic phase Rhodotorula mucilaginosa 49 cells grown with glucose as substrate in the presence of $0.04 \% \mathrm{~K}_{2} \mathrm{TeO}_{3}$ gave poor contrast. Because poststaining did not obscure the reduction product, all micrographs were of poststained sections.

The electron-opaque reduction product was granular and was deposited only on areas of endoplasmic reticulum near the nucleus (Pl. I, fig. 2; Pl. 2, fig. 3, 4), areas of endoplasmic reticulum which were absent in control cells. This endoplasmic reticulum was of the tubular type, densely packed and showing much branching. No conclusion can be drawn as to the chemical nature of the reduction product. It was not in the form of crystalline tellurium but consisted of granules in close association with membranes of the endoplasmic reticulum (Pl. I, fig. 2). In addition to the endoplasmic reticulum involved in tellurite reduction, other unbranched lengths of it were present without associated reduction product (Pl. 2, fig. 3).

When sodium malate, a specific respiratory substrate, replaced glucose in the culture medium, in the presence of $0.04 \% \mathrm{~K}_{2} \mathrm{TeO}_{3}$ the cells reduced tellurite at the same site as when glucose was substrate (Pl. 2, fig. 5). Dense deposits of reduction product were found on endoplasmic reticulum complexes connected to the nuclear membrane, though the latter had no reduction product associated with it.

\section{Electron microscopy of Saccharomyces cerevisiae I-434}

For electron microscopy, Saccharomyces cerevisiae I-434 was grown with $4 \%$ $(\mathrm{w} / \mathrm{v})$ melibiose as the carbon source. Melibiose, a non-repressing fermentable substrate, gave rise to membranes that preserved well (Marchant \& Smith, 1968). The endoplasmic reticulum was less well-defined in $S$. cerevisiae I-434 than in Rhodotorula mucilaginosa 49 when fixed in permanganate, and was mainly oriented around the periphery of the cell inside the plasmalemma (Pl. 3, fig. 6). Another difference was that the mitochondrial cristae were more numerous and prominent in $R$. mucilaginosa 49.

Cells of Saccharomyces cerevisiae $\mathrm{I}-434$ grown with $0.04 \% \mathrm{~K}_{2} \mathrm{TeO}_{3}$ on melibiose showed two types of endoplasmic reticulum (Pl. 3, fig. 7, 8) similar in distribution to those found in tellurite-grown cells of Rhodotorula mucilaginosa 49. The reduction product was less prominent than in $R$. mucilaginosa 49 , but was also deposited on localized areas of branched endoplasmic reticulum near the nucleus and in connexion with the nuclear membrane (PI. 3, fig. 7). The normal endoplasmic reticulum was sometimes difficult to distinguish from the endoplasmic reticulum involved in reduction, as the two types were often not clearly separated, but both could be recognized (Pl. 3, fig. 8).

\section{DISCUSSION}

Studies of enzyme localization are valid only if the electron-dense product does not diffuse away from the site of deposition. The tellurite reduction product, tellurium, is insoluble in water and in organic solvents, but it is soluble in hot sulphuric acid and 
Bromine water (Nermut, 1963). Although the reduction product has not been identified as tellurium in yeasts, Barnett \& Palade (1957) and van Iterson \& Leene (1964) consider that the granular product of tellurite reduction is deposited at the site of reduction and does not diffuse away.

Rhodotorula mucilaginosa 49 and Saccharomyces cerevisiae I-434 reduced tellurite on localized branched areas of endoplasmic reticulum. These branched forms were absent in normally grown yeasts. It is postulated that the branching systems of membranes carried an enzyme or enzymes that reduced the tellurite which were not present on the normal lengths of less-branched endoplasmic reticulum.

Because potassium permanganate does not fix ribosomes, it does not permit a distinction between rough and smooth endoplasmic reticulum. Hence it is possible that the two types of endoplasmic reticulum observed in the present study differed in this respect. The above ultrastructural study implies that when a cell is exposed to a high internal concentration of tellurite ions, one type of endoplasmic reticulum proliferates and increases in its content of a particular enzyme or enzymes. This probably occurs with selenite as well, since Nickerson (1954) found that Candida albicans reduced tellurite and selenite in particulate loci, and these for tellurite are here demonstrated to be complexes of endoplasmic reticulum.

Barnett \& Palade (I957) and Bisaltputra, Brown \& Weier (I969) have concluded that dehydrogenases are the primary enzymes involved in tellurite reduction and that respiratory dehydrogenases are located by this reaction. However, respiratory and cytochemical studies on Rhodotorula mucilaginosa 49 indicated that tellurite reduction was not mediated by respiratory enzymes. Up to $0.08 \% \mathrm{~K}_{2} \mathrm{TeO}_{3}$ had no effect on the rate of oxygen uptake, and when this yeast was grown on a respiratory substrate (sodium malate) in the presence of $0.04 \% \mathrm{~K}_{2} \mathrm{TeO}_{3}$ reduction was still confined to localized areas of endoplasmic reticulum, and no reduction product was visible on the mitochondrial membranes.

In Saccharomyces cerevisiae I-434 oxygen uptake is progressively inhibited by increasing concentrations of potassium tellurite. Furthermore, this yeast does not multiply in the presence of glycerol and tellurite, which indicates that respiration is completely inhibited. It appears therefore that the respiratory enzyme system of the facultative anaerobe $S$. cerevisiae $\mathrm{I}-434$ is sensitive to tellurite whereas respiratory enzymes in the obligate aerobe Rhodotorula mucilaginosa 49 are not.

Although the respiratory systems of the two yeasts showed different sensitivities to tellurite, the actual site of reduction was the same for both organisms, namely on a complex of branching endoplasmic reticulum.

This work was supported by a grant to P. S. C. from the Science Research Council.

\section{REFERENCES}

Barnett, R. J. \& Palade, G. E. (1957). Histochemical demonstration of the sites of activity of dehydrogenase systems with the electron microscope. Journal of Biophysical and Biochemical Cytology 3, 577-588.

Bisaltputra, T., Brown, D. L. \& Weier, T. E. (1969). Possible respiratory sites in a blue-green alga, Nostoc sphaericum, as demonstrated by potassium tellurite and tetranitro blue tetrazolium. Journal of Ultrastructure Research 27, I82-197.

BRIEgER, E. M. (1963). In Structure and Ultrastructure of Micro-organisms, chap. 19. New York: Academic Press.

22

M I C 63 
VAN Iterson, W. \& LeENe, W. (1964). A cytochemical localization of reductive sites in a Grampositive bacterium. Tellurite reduction in Bacillus subtilis. Journal of Cell Biology 20, 361-376.

Johansen, D. A. (1940). Plant Microtechnique. New York: McGraw-Hill.

Marchant, R. \& Smith, D. G. (1968). Membranous structures in yeasts. Biological Reviews 43, 459-480.

NAGAI, S. (1965). Differential reduction of tellurite by growing colonies of normal yeast and respiration deficient mutants. Journal of Bacteriology 90, 220-222.

Nermut, M. V. (1963). Determination of tellurium in the cells of Gram-negative bacteria. Folia Microbiologica, Praha 8, 370.

Nermut, M. V. (1967). Sites of 'glycine oxidase' activity in Proteus vulgaris. Canadian Journal of Microbiology 13, 551-556.

NiCKERSON, W. J. (I954). An enzymatic locus participating in cellular division of a yeast. Journal of General Physiology 37, 483-494.

REYNOLDS, E. S. (1963). The use of lead citrate at high $\mathrm{pH}$ as an electron-opaque stain in electron microscopy. Journal of Cell Biology 17, 208-2 12.

TCHAN, Y. T. \& WEBBER, A. J. (I966). Fine structure and tellurite reduction in Azotobacter vinelandii. Archiv für Mikrobiologie 54, 21 5-228.

\section{EXPLANATION OF PLATES}

Abbreviations: $n$, nucleus; $m$, mitochondrion; $v$, vacuole; er, endoplasmic reticulum; te, reduction product

\section{Plate I}

Fig. I. Normal cell of Rhodotorula mucilaginosa 49 grown to midlogarithmic phase in glucose-salts medium. $\times 40,500$.

Fig. 2. Section of a $R$. mucilaginosa 49 cell, grown in glucose-salts medium in the presence of $0.04 \%$ $\mathrm{K}_{2} \mathrm{TeO}_{3}$. Granular reduction product is deposited on a localized area of endoplasmic reticulum. $\times 80,000$.

Plate 2

\section{Potassium tellurite reduction in Rhodotorula mucilaginosa 49}

Fig. 3. Midlogarithmic phase cell grown in a glucose-salts medium with $0.04 \% \mathrm{~K}_{2} \mathrm{TeO}_{3}$. Tellurite reduction occurs on the area of densely packed endoplasmic reticulum near the nucleus $\left(\mathrm{er}_{1}\right)$. Other lengths of endoplasmic reticulum not involved in reduction are present near the cell membrane $\left(\mathrm{er}_{2}\right)$. $\times 56,000$.

Fig. 4. Cell grown under the same conditions as described for fig. 3. The reduction product is visible on the localized area of branching endoplasmic reticulum near the nucleus. $\times 57,600$.

Fig. 5. Section of a cell grown on sodium malate in the presence of $0.04 \% \mathrm{~K}_{2} \mathrm{TeO}_{3}$. Reduction product is deposited on the membranes of the endoplasmic reticulum, which is itself connected to the nuclear membrane. $\times 68,000$.

\section{Plate 3}

Fig. 6. Control cell of Saccharomyces cerevisiae I-434 grown on melibiose. The mitochondrial membranes are poorly defined and the endoplasmic reticulum is oriented mainly around the periphery of the cell. $\times 41,600$.

Fig. 7. Midlogarithmic phase cell of $S$. cerevisiae $\mathrm{x}-434$ grown on $0.04 \% \mathrm{~K}_{2} \mathrm{TeO}_{3}$ and melibiose. Reduction product is deposited on the area of endoplasmic reticulum in connexion with the nuclear membrane $\left(\mathrm{er}_{1}\right)$. The normal endoplasmic reticulum around the periphery of the cell $\left(\mathrm{er}_{2}\right)$ is not involved with reduction. $\times 54,000$.

Fig. 8. S. cerevisiae $\mathrm{I}-434$ grown under the same conditions as in fig. 7. The reduction product is restricted to an area of branching endoplasmic reticulum, not present in normal cells $\left(\mathrm{er}_{1}\right)$; $\mathrm{er}_{2}$, normal endoplasmic reticulum. $\times 50,000$. 

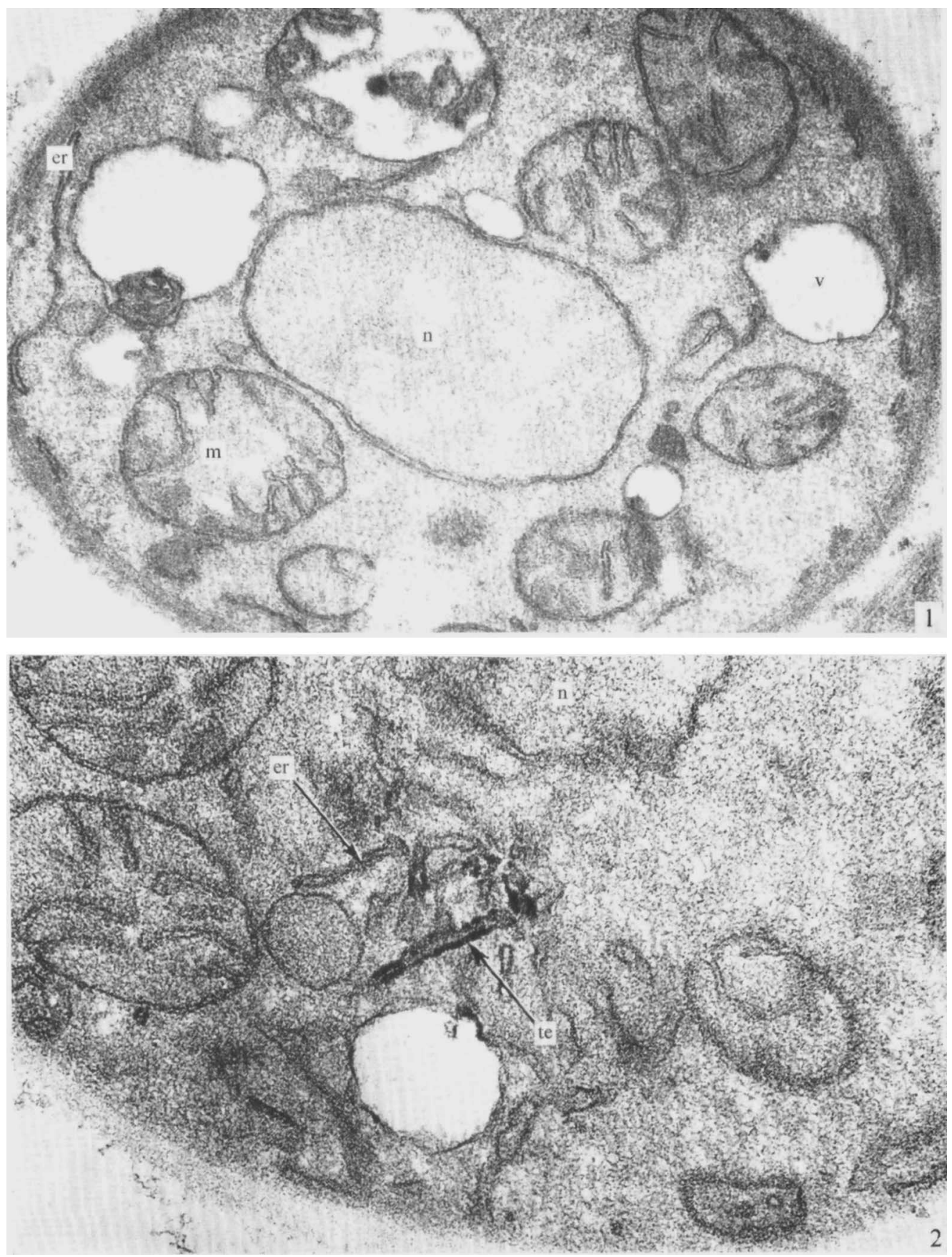

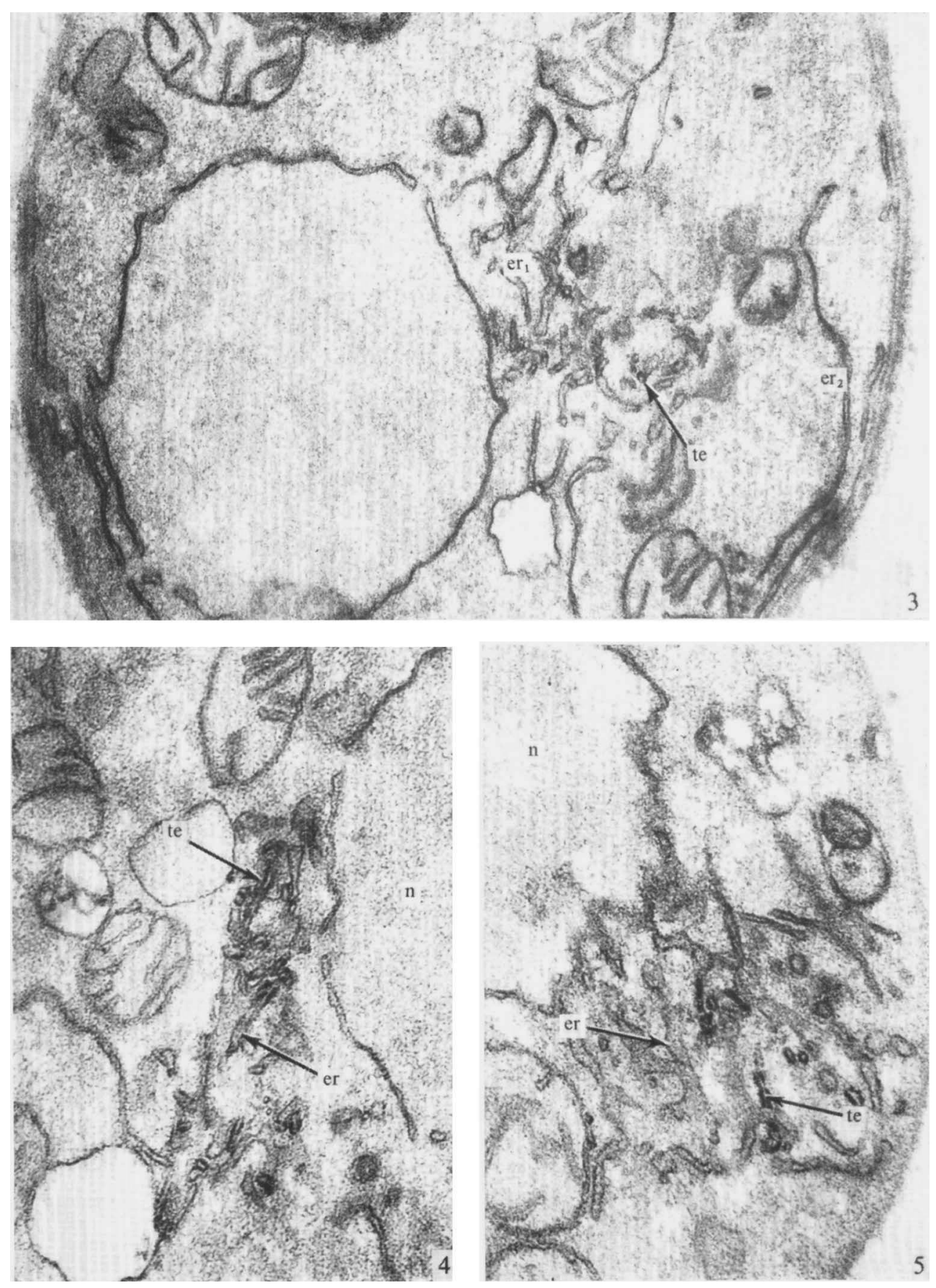

P. S. CORFIELD AND D. G. SMITH 

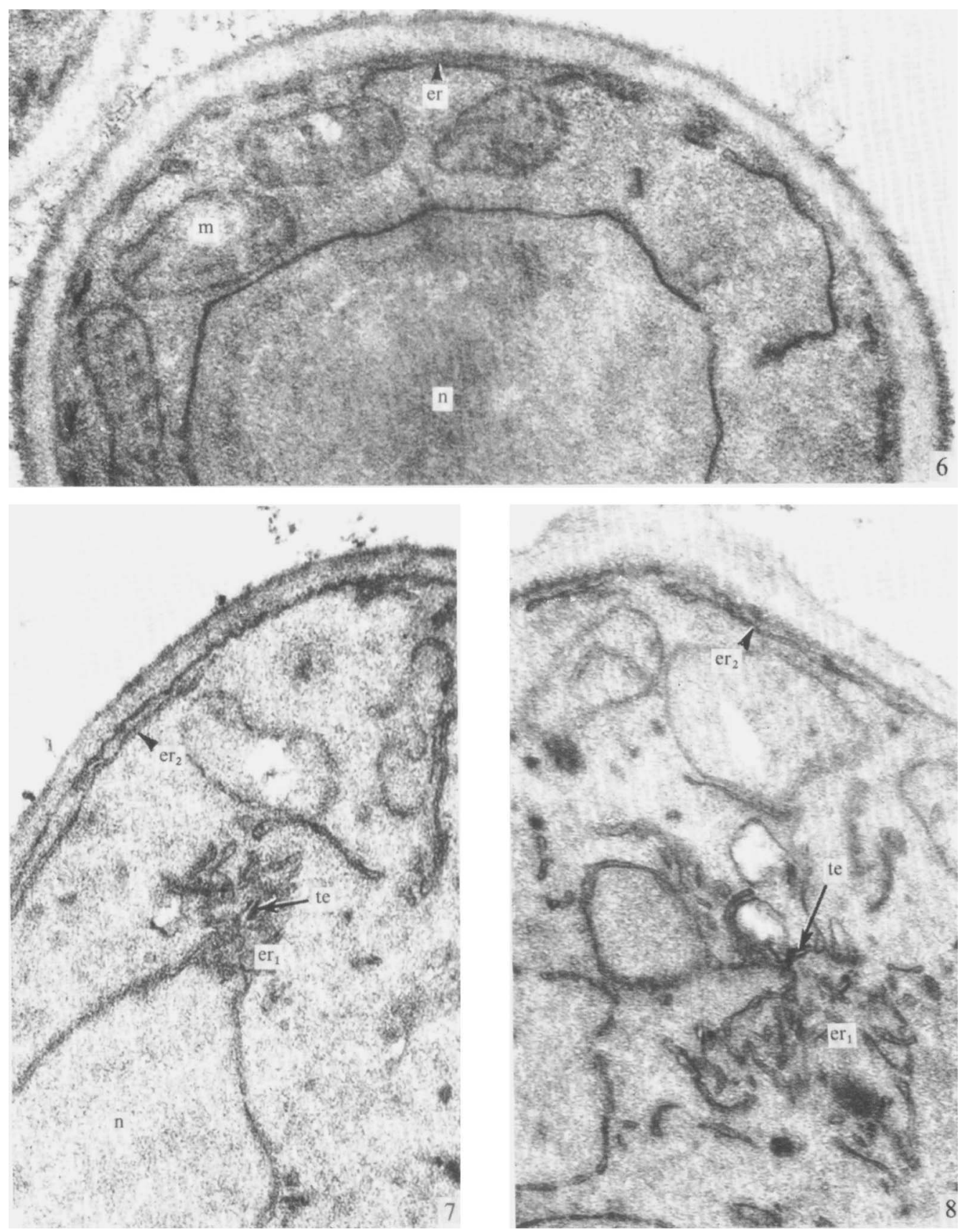

P. S. CORFIELD AND D. G. SMITH 